\title{
UVB radiation induces human lens epithelial cell migration via NADPH oxidase-mediated generation of reactive oxygen species and up-regulation of matrix metalloproteinases
}

\author{
JIN YAO ${ }^{1}$, YUAN LIU ${ }^{1}$, XINRU WANG ${ }^{1}$, YI SHEN $^{1}$, SONGTAO YUAN ${ }^{1}$, YINSHENG WAN $^{2}$ and QIN JIANG ${ }^{1}$ \\ ${ }^{1}$ Eye Hospital, Nanjing Medical University, Nanjing, P.R. China; \\ ${ }^{2}$ Department of Biology, Providence College, Providence, RI 02918, USA
}

Received January 19, 2009; Accepted April 2, 2009

DOI: 10.3892/ijmm_00000218

\begin{abstract}
Ultraviolet (UV) radiation is one of the important cataract risk factors. The migration of human lens epithelial cells (HLECs) plays a crucial role in the remodeling of lens capsule and cataract formation. The purpose of the present study was to investigate the molecular mechanisms of UVinduced lens cell migration. We found that UVB radiation induces cell migration in cultured human lens epithelial cells. Further, we observed that UVB radiation induces NADPH oxidase activity and ROS generation which are inhibited by NADPH oxidase inhibitor diphenylene iodonium or DPI and antioxidant epigallocatechin gallate (EGCG). In addition, DPI and EGCG also block UVB irradiation-induced MMP-2, and -9 activity and expression and nuclear translocation of NF-кB. Collectively, our data suggest that NADPH oxidase may be a major source for the UVB-induced ROS generation, and it plays an essential role in the activation of $N F-\kappa B$, which is involved in the activities of MMP-2 and MMP-9 and cell migration induced by UVB in HELCs. Understanding the cell signaling pathways may constitute potential therapeutic targets in for UVB-induced cataract.
\end{abstract}

\section{Introduction}

Cataract is a common disease of the lens and is the leading cause of blindness worldwide. Among the multiple factors affecting cataractogenesis, ultraviolet $B$ irradiation (UVB) has received much attention, as the lens is regarded as an accumulating site of oxidative insults from radiant energy,

Correspondence to: Dr Qin Jiang, Eye Hospital, Nanjing Medical University, Nanjing 210029, P.R. China

E-mail: jqin710@vip.sina.com

Dr Yinsheng Wan, Department of Biology, Providence College, 549 River Ave, Providence, RI 02918-0001, USA

E-mail: yswan@providence.edu

Key words: UVB radiation, NADPH oxidase, matrix metalloproteinases including photo-oxidation by UVB $(1,2)$. The notion that UV radiation could result in the lens opacification has been supported by accumulating epidemiologic and animal studies $(3,4)$. The photo-biological effects of UVB may attack oxidative pathways involved in the generation of reactive oxygen species (ROS) (5) which induce directly oxidative damage to DNA (6), deregulation of normal matrix dynamics and degradation of collagen (7). Recent studies have shown that the abnormal proliferation and migration of lens epithelial cells (LECs) at the equator and underneath the anterior lens capsule are induced by several risk factors, such as alcohol, fat, diabetes and UV light, leading to the development of cataract $(8,9)$. However, the cellular processes are poorly understood.

Repopulation of the posterior capsule by LECs migration leading to capsule opacification (accompanied by capsule wrinkling and contraction) and matrix production could result in a cataract $(8,9)$. Matrix metalloproteinases (MMPs) are a family of zinc-dependent endopeptidases, which are essential for cell migration and cell mediated contraction following wound healing (10). MMPs may play a very important role in cataract formation. MMPs and tissue inhibitors have been examined in both the normal and cataractous lens $(11,12)$. MMP inhibition prevents human lens epithelial cell migration and contraction of the lens capsule $(13,14)$. Addition of stress factors including cytokines, surgery and UV induces the dysregulation of MMP activity that may be responsible for cataract formation $(7,12)$. A recent study showed that MMP-2 and MMP-9, which degrade type IV collagen in the basement membrane, are involved in hydrogen peroxideinduced cataract formation (15). However, the cell signaling mechanism of MMPs-induced migration remains to be explored.

Nuclear factor kappa B or NF-кB is a redox-regulated transcription factor and is involved in the expression of a wide variety of pro-inflammatory cytokine genes and matrix metalloproteinases (16). Recent studies have shown that $\mathrm{NF}-\kappa \mathrm{B}$ activation is required for MMP-9 gene expression (17). Upon stimulation, $\mathrm{NF}-\kappa \mathrm{B}$ translocates into nucleus, where it further transcribes target genes involved in many important cellular events. It also plays a critical role in determining cellular responses to extracellular stimuli. Although UVB is the well-characterized stimulus for ROS generation 
in some cell lines, however, the association between NF-кB activation and ROS and NADPH oxidase activity in response to UVB has remained relatively unexplored.

The present study investigates whether UVB induces HLEC migration via NADPH oxidase-mediated generation of ROS and activation of NF- $\mathrm{B}$ which leads to up-regulation of MMP-2 and MMP-9.

\section{Materials and methods}

UV light apparatus. Consistent with previous studies (18), the UV irradiation apparatus used in this study consisted of four F36T12 UV tubes. A Kodacel TA401/407 filter was mounted $4 \mathrm{~cm}$ in front of the tubes to remove wavelengths $\leq 290 \mathrm{~nm}$ (UVC). Irradiation intensity was monitored using an IL443 phototherapy radiometer and a SED240/UV/W photodetector. Before UV irradiation, cells were washed with PBS and then changed to $0.5 \mathrm{ml}$ PBS in each well. Cells were irradiated at a desired intensity without a plastic dish lid. After UV irradiation, cells were put back to incubation in basal DMEM with treatments at various time points prior to harvesting.

Cell culture. Human lens epithelial cells (cell line) were obtained from Dr Fu Shang at Tufts University. Cells were maintained in Dulbecco's modified Eagles's medium (DMEM, Gibco Life Technologies) supplemented with $15 \%$ fetal bovine serum (Hyclone), penicillin/streptomycin (1:100, Sigma) and $4 \mathrm{mM}$ L-glutamine and 0.19\% HEPES, in a humid atmosphere incubator with $5 \% \mathrm{CO}_{2}$ at $37^{\circ} \mathrm{C}$. Cells were reseeded in 6-well plates at a density of $0.2 \times 10^{6}$ cells $/ \mathrm{ml}$ with fresh complete culture medium. Prior to treatment, cultures were grown to $70-80 \%$ confluence and given another serum-starved condition overnight in DMEM medium prior to treatment.

Cell migration assay. As previously described (15), one milliliter of a $1 \times 10^{6}$ cells $/ \mathrm{ml}$ suspension in $10 \%$ FBS-DMEM was added to each well of a $60-\mathrm{mm}$ tissue culture plate and cultured for $24 \mathrm{~h}$, and then incubated with $10 \mathrm{mg} / \mathrm{l}$ mitomycin in order to inhibit the cell proliferation, at $37^{\circ} \mathrm{C}$ for $2 \mathrm{~h}$. A straight-edge razor blade was used to denude two $10 \times 5 \mathrm{~mm}$ areas in each well of cells. After exposure to $30 \mathrm{~mJ} / \mathrm{cm}^{2} \mathrm{UVB}$ irradiation, the cultures were washed 2 times with PBS to remove floating cells. DMEM with $10 \%$ FBS was used as chemo-attractant. After the treatment, cells were cultured at $37^{\circ} \mathrm{C}$ and $48 \mathrm{~h}$ later migration of cells into a denuded area of the cultures was quantified.

NADPH oxidase assay. For measurements of NADPH oxidase activity, UVB-irradiated cells were washed several times with ice-cold PBS, scraped from the plate in PBS, and transferred to a centrifuge tube. After centrifugation at $1000 \mathrm{x} \mathrm{g}$ and $4^{\circ} \mathrm{C}$ for $10 \mathrm{~min}$, pellets were resuspended in icecold lysis buffer (20 mM potassium phosphate, $\mathrm{pH} 7.0,1 \mathrm{mM}$ EGTA, $10 \mu \mathrm{g} / \mathrm{ml}$ aprotinin, $10 \mu \mathrm{g} / \mathrm{ml}$ leupeptin, $1 \mu \mathrm{M}$ pepstatin, 0.5 mM PMSF) and homogenized with a homogenizer. Prior to UVB irradiation, cells were treated with DPI $(10 \mu \mathrm{M})$ or EGCG $(100 \mu \mathrm{g} / \mathrm{ml})$ for $1 \mathrm{~h}$. NADPH oxidase activity was measured as previously described (19).

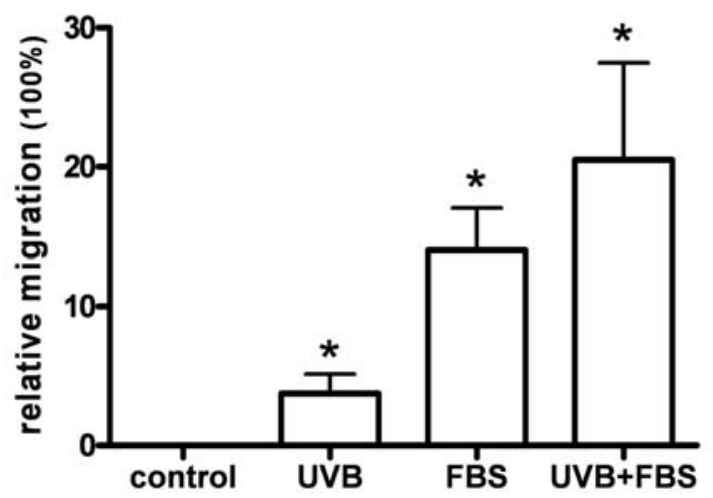

Figure 1. UVB radiation induces HLEC cell migration. When the cells were at $70-80 \%$ confluence, the proliferation was inhibited by mitomycin. DMEM with $20 \%$ FBS was used as chemo-attractant. After UVB $\left(30 \mathrm{~mJ} / \mathrm{cm}^{2}\right)$ treatment, the cells with or without $20 \%$ FBS were cultured for another $24 \mathrm{~h}$. The migration of cells into a denuded area of the culture was quantified. Relative migration $=($ the numbers of treatment group cells - the control group cells)/ the numbers of control group cells. Data are average of several visual fields from one experiment, representative of at least two separate experiments with similar results. Each value represents the mean \pm SD *Significant difference, compared with control group.

FACS analysis. Cultured human lens epithelial cells were deprived of serum for $24 \mathrm{~h}$ and loaded with $20 \mu \mathrm{M}$ of a fluorescent dye, dihydrorhodamine (DHR) that reacts with ROS in cells and results in fluorescence. Cells were irradiated with UVB $\left(30 \mathrm{~mJ} / \mathrm{cm}^{2}\right)$, and were then collected and fixed, the generation of ROS of treated cells was measured by FACS analysis. Induction of ROS generation was expressed in arbitrary units.

Immunocytochemistry. Cells were seeded in $60 \mathrm{~mm}$ plates (Fisher Scientific, USA) at a density of $5 \times 10^{5}$ cells $/ \mathrm{ml}$ with fresh complete culture medium, and incubated for $24 \mathrm{~h}$ in a $\mathrm{CO}_{2}$ incubator. Cells were grown to $70-80 \%$ confluence and then serum-starved overnight in DMEM medium prior to UV $\left(30 \mathrm{~mJ} / \mathrm{cm}^{2}\right)$, and collected at $4 \mathrm{~h}$. Prior to UVB irradiation, cells were treated with DPI $(10 \mu \mathrm{M})$ or EGCG $(100 \mu \mathrm{g} / \mathrm{ml})$ for $1 \mathrm{~h}$. After treatment, the cells were washed with cold PBS. The cells were then fixed with $3.7 \%$ formaldehyde/PBS at room temperature for $5 \mathrm{~min}$ and washed with cold PBS, incubated with $800 \mu 1$ of $3 \%$ BSA/0.3\% NP40/PBS for $30 \mathrm{~min}$, at room temperature, washed twice with PBS for $15 \mathrm{~min}$, and incubated with anti-NF- $\mathrm{KB}$ p65 for $1 \mathrm{~h}$ at $25^{\circ} \mathrm{C}$. After washing with PBS, the cells were exposed to FITC-conjugated anti-rabbit antibody for $1 \mathrm{~h}$ in the dark. FITC labeled cells were rinsed and stained with PI for $30 \mathrm{~min}$ in the dark. After washing with PBS, cells were visualized in the fluorescence microscope (Olympus) attached to an image analyzing system.

Western blot analysis. Cultured human lens epithelial cells with and without treatment were washed with cold PBS and harvested by scraping into a centrifuge tube. After centrifugation at $2,000 \mathrm{rpm}$ and $4^{\circ} \mathrm{C}$ for $5 \mathrm{~min}$, pellets were resuspended with $200 \mu 1$ of $\mathrm{HB}$ buffer (contain $10 \mathrm{mM}$ Tris $\mathrm{pH} 7.9,1.5 \mathrm{mM} \mathrm{MgCl}_{2}, 10 \mathrm{mM} \mathrm{KCl}$ ) with $0.2 \%$ Triton $\mathrm{X}-100$, and gently inverted 5 times. After centrifugation at $1000 \mathrm{x} \mathrm{g}$ and $4^{\circ} \mathrm{C}$ for $10 \mathrm{~min}, 200 \mu \mathrm{l}$ of cytoplasmic fraction was 


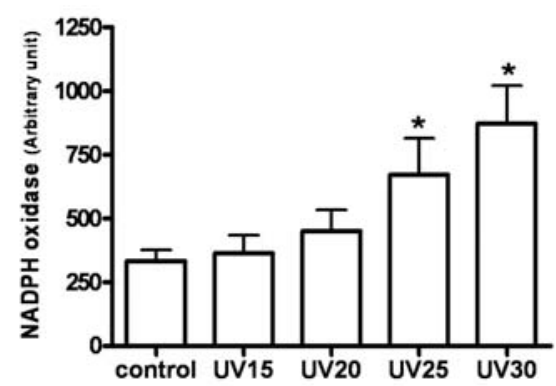

B

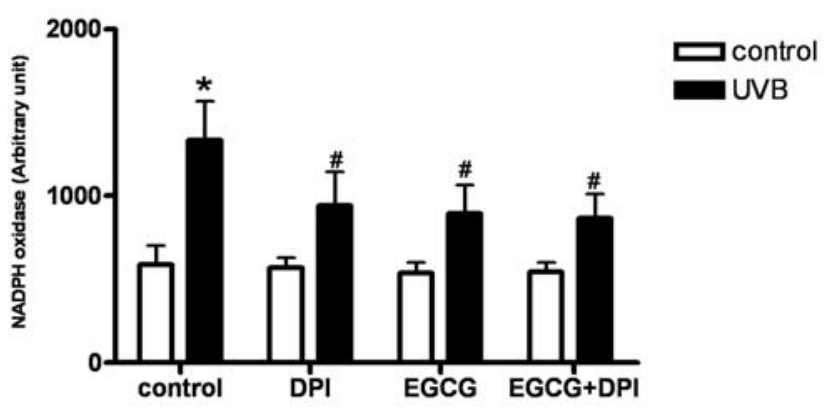

Figure 2. UVB induces NADPH oxidase activity in HLECs which is inhibited by DPI and EGCG. After treatment, the cells were harvested at 30 min. NADPH oxidase activity in cell lysates was analyzed as described in Materials and methods. (A) Cells were treated with different irradiation of UVB. (B) Effect of UVB $\left(30 \mathrm{~mJ} / \mathrm{cm}^{2}\right)$ on NADPH oxidase activity in the absence and presence of DPI $(10 \mu \mathrm{M})$, with or without co-incubation with EGCG $(100 \mu \mathrm{g} / \mathrm{ml})$. The activity was expressed in arbitrary units (A and B) with the mean $\pm \mathrm{SD}{ }^{*} \mathrm{P}<0.05$ vs. untreated LECs cells; ${ }^{*} \mathrm{P}<0.05$ vs. absence of UVB $\left(30 \mathrm{~mJ} / \mathrm{cm}^{2}\right)$.

mixed with $10 \mu \mathrm{l}$ of $5 \mathrm{M} \mathrm{NaCl}$. The pellets were washed with $\mathrm{HB}$ buffer and centrifuged at $1000 \mathrm{x}$ g. Pellets were resuspended with $100 \mu 1$ of RIPA buffer containing $50 \mathrm{mM}$ Tris$\mathrm{HCl}(\mathrm{pH} 7.4), 150 \mathrm{mM} \mathrm{NaCl}, 1 \% \mathrm{NP} 40,1 \mathrm{mM}$ EDTA, $0.25 \%$ sodium deoxycholate, $1 \mathrm{mM} \mathrm{NaF}, 10 \mu \mathrm{M} \mathrm{Na}_{3} \mathrm{VO}_{4}$, $1 \mathrm{mM}$ phenylmethylsulfonyl fluoride, and protease inhibitor cocktail $(10 \mu \mathrm{g} / \mathrm{ml}$ aprotinin, $10 \mu \mathrm{g} / \mathrm{ml}$ leupeptin and $1 \mu \mathrm{M}$ pepstatin) and $50 \mathrm{mM} \mathrm{NaCl}$. Cell lysates were incubated at $4^{\circ} \mathrm{C}$ for $30 \mathrm{~min}$. After centrifugation at $14,000 \mathrm{rpm}$ for $10 \mathrm{~min}$ at $4^{\circ} \mathrm{C}$, the protein concentration was determined by Bio-Rad protein assay (Bio-Rad, Hercules, CA). Cytosolic and nuclear proteins were separated by $10 \%$ SDS-PAGE and transferred to Immobilon-P membrane (Millipore, Bedford, MA). After incubation with a primary anti-NF-кB p65 or GAPDH or anti-Lamin B M20 (Santa Cruz Biotechnology, Santa Cruz, CA) followed by horseradish peroxidaseconjugated anti-rabbit IgG antibody and anti-mouse IgG antibody (Cell Signaling Technology, Inc, Beverly, MA). Antibody binding was detected using an enhanced chemiluminescence (ECL) detection system (GE Biosciences) following the manufacturer's instruction and visualized by autoradiography with Hyperfilm.

Gelatin zymography. Cell-conditioned medium was subjected to substrate gel electrophoresis with some modifications. The samples were applied without reduction to a $10 \%$ (W/V) polyacrylamide gel impregnated with $1 \mathrm{mg} / \mathrm{ml}$ gelatin (Sigma,
St. Louis, MO). After electrophoresis, the gel was washed in washing buffer (50 mM Tris- $\mathrm{HCl}, \mathrm{pH} 7.4,5 \mathrm{mM} \mathrm{CaCl}_{2}, 1 \mu \mathrm{M}$ $\mathrm{ZnCl}_{2}, 2.5 \%$ Triton $\mathrm{X}-100$ ) for $30 \mathrm{~min}$ at room temperature, and then incubated overnight at $37^{\circ} \mathrm{C}$ with shaking in the same buffer, except that Triton $\mathrm{X}-100$ was present at $1 \%$. The gel was stained with a solution of $0.1 \%$ Coomassie Brilliant Blue R-250. In this assay, clear zones against the blue background indicate the presence of gelatinolytic activity. Quantification of bands was performed by densitometry.

RT-PCR assay. Total RNA was isolated from cells with an RNA isolation kit (RNAzol, Tel-Test, Freincs-wood and TX) and reverse-transcribed according to the manufacturer. PCR was performed with an initial denaturation for $30 \mathrm{sec}$ at $94^{\circ} \mathrm{C}$, annealing at $55^{\circ} \mathrm{C}$ for $30 \mathrm{sec}$ and extension at $72^{\circ} \mathrm{C}$ for $45 \mathrm{sec}$, for 35 cycles. Primer sequences used were as follows: ß-actin forward, CTACAATGAGCTGCGTGTGGC; $ß$-actin reverse, CAGGTCCAGACGCAGGATGGC; MMP-2 forward, ACC TACACCAAGAACTTCCG; MMP-2 reverse, TTGGTTCTCCAGCTTCAGGT; MMP-9 forward, CCC ATTTCGACGATCAC; MMP-9 reverse, GGCACTGAC CAATGATCTAAGC. PCR products were separated by $2 \%$ agarose gel electrophoresis and visualized with ethidium bromide. The bands were quantified by densitometry and normalized with $\beta$-actin.

Statistical analysis. The values in the figures are expressed as the mean \pm standard deviation (SD). Statistical analysis of the data between the control and treated groups was performed by the Student's t-test. Values of $\mathrm{P}<0.05$ were considered as significant.

\section{Results}

$U V B$ radiation induces $H L E C$ cell migration. To understand whether UVB irradiation induces HLEC migration, we cultured the cells in $60 \mathrm{~mm}$ plates. When the cells were at $70-80 \%$ confluence, the proliferation was inhibited by mitomycin. DMEM with 20\% FBS was used as chemo-attractant. After treatment, LEC was cultured for another $48 \mathrm{~h}$. And the migration of cells into a denuded area of the cultures was quantified. As shown in Fig. 1, UVB irradiation $\left(30 \mathrm{~mJ} / \mathrm{cm}^{2}\right)$ induces LEC migration and UVB irradiation with $20 \%$ FBS also significantly induces the LEC migration. The results suggest that UVB induces the migration of LEC which may play an important part in the development of cataract and posterior capsule opacification.

Roles of NADPH oxidase in UVB-induced ROS generation in HLECs. It has been known that UVB activates oxidative pathways involved in the generation of reactive oxygen species (ROS). Our recent study showed that antioxidant quercetin exhibits a protective effect against UVB-induced cataract formation (20). ROS is generated through various pathways, including NADPH oxidase-mediated pathway. To test the hypothesis that UV-induced ROS is mediated by NADPH oxidase in culture human lens cells, we directly measured NADPH oxidase activity post-UV radiation and the ROS production when NADPH oxidase was inhibited. The data show that UVB induces NADPH oxidase activity in 
A

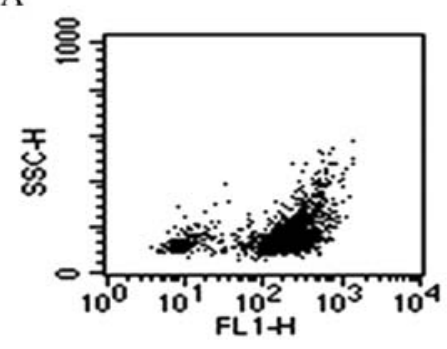

Control

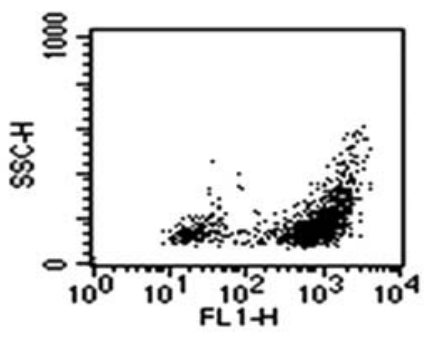

UV+DPI

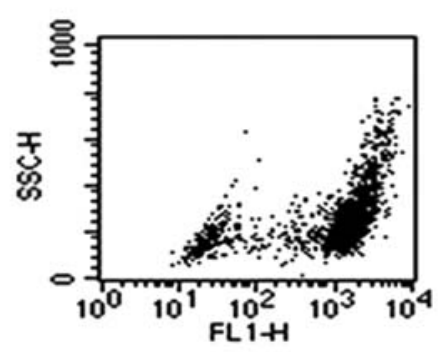

UV $30 \mathrm{mj} / \mathrm{cm}^{2}$

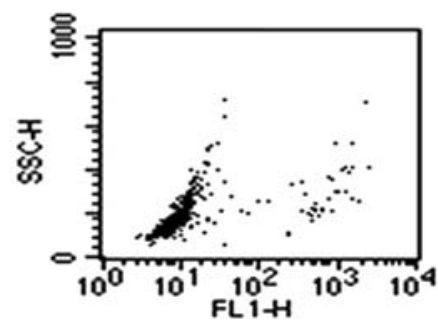

UV+EGCG

B

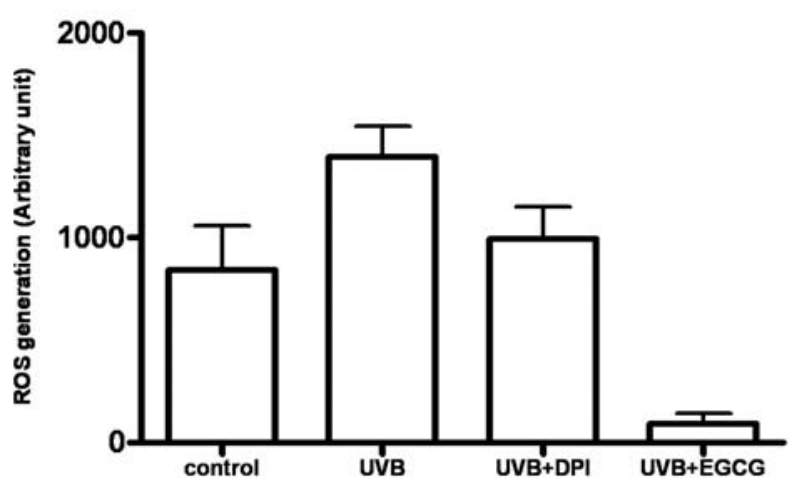

Figure 3. UVB-induced ROS generation is partly mediated by NADPH oxidase. HLECs were pre-incubated with DPI (10 $\mu \mathrm{M})$ or EGCG (100 $\mu \mathrm{g} / \mathrm{ml})$ for $1 \mathrm{~h}$. After UVB $\left(30 \mathrm{~mJ} / \mathrm{cm}^{2}\right)$ irradiation, cells were loaded with DHR $(20 \mu \mathrm{M})$ for $1 \mathrm{~h}$, collected and fixed at 30 min post-treatment for FACS analysis (A). Induction of ROS generation is expressed in arbitrary units $(B)$ as the mean \pm SD of triplicate experiments.

a dose-dependent manner (Fig. 2A). DPI (an NADPH oxidase inhibitor) and EGCG (an antioxidant) treatment inhibit the activity of NADPH oxidase (Fig. 2B).

FACS analysis showed that UVB $\left(30 \mathrm{~mJ} / \mathrm{cm}^{2}\right)$ induces ROS production, while DPI and EGCG reduces ROS production (Fig. 3). The data suggest that UVB induces ROS generation partly through NADPH oxidase pathway. EGCG is a nature antioxidant which has shown a beneficial effect on cardiovascular diseases. In our study, we observed that EGCG treatment significantly reduces the intracellular ROS, suggesting that EGCG is not only an antioxidant but also acts as a ROS scavenger.

Effect of UVB irradiation on MMP-2, MMP-9 $m R N A$ and activities. We have shown that UVB irradiation induces LECs migration. To further understand cellular mechanisms, we measured MMP-2, MMP-9 mRNA and activities. After UVB $\left(30 \mathrm{~mJ} / \mathrm{cm}^{2}\right)$ irradiation, the cells, which were preincubated with DPI $(10 \mu \mathrm{M})$ or EGCG $(100 \mu \mathrm{g} / \mathrm{ml})$, were cultured for another $24 \mathrm{~h}$. The culture media were collected for gelatin zymography analysis. The results showed that UVB irradiation increases the activities of MMP-2 and MMP-9 significantly. Treatment with DPI (NADPH oxidase inhibitor) inhibits UVB-induced MMP-2 and MMP-9 activation. EGCG (antioxidant) also decreases MMPs activation induced by UVB (Fig. 4). RT-PCR results showed that UVB treatment increases the MMP-2 and MMP-9 mRNA levels which are partly blocked by DPI (NADPH oxidase inhibitor) and EGCG (Fig. 5). These results suggest that up-regulation of MMPs by UVB may be partly mediated by NADPH oxidase.

Roles of NADPH oxidase in UVB-induced nuclear translocation of $N F-\kappa B$. We have shown that UVB induces human lens epithelial cell migration via NADPH oxidasemediated generation of reactive oxygen species and upregulation of matrix metalloproteinases. To further investigate the signal transduction pathways, we measured the activation of NF- $\kappa \mathrm{B}$, a redox-regulated transcription factor which is involved in the expression of matrix metalloproteinases (16). 
A

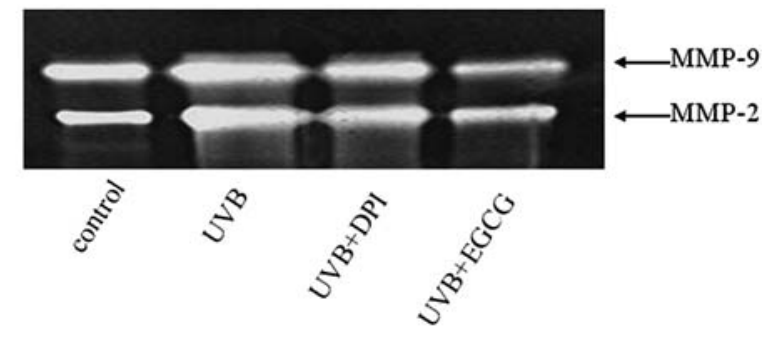

B

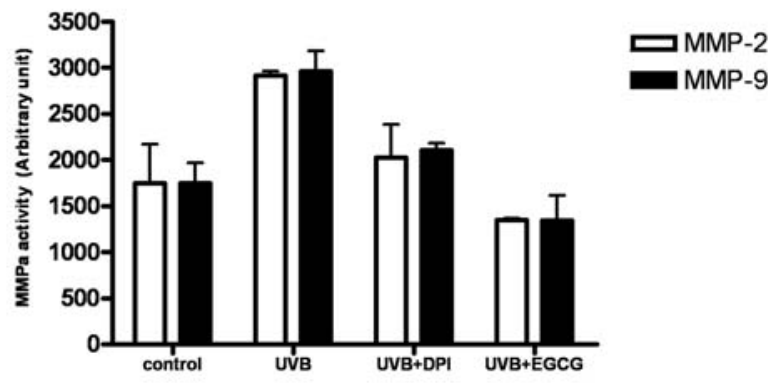

Figure 4. UVB induces MMP-2 and MMP-9 activities which are inhibited by DPI and EGCG. (A) HLECs were pre-incubated with DPI $(10 \mu \mathrm{M})$ or EGCG $(100 \mu \mathrm{g} / \mathrm{ml})$ for $1 \mathrm{~h}$. After UVB $\left(30 \mathrm{~mJ} / \mathrm{cm}^{2}\right)$ irradiation, the cells were cultured for another $24 \mathrm{~h}$. The culture media were collected and loaded on a $10 \%$ SDS-polyacrylamide gel containing $1 \mathrm{mg} / \mathrm{ml}$ denature gelatin. The clear zone on a dark background after staining represented MMP activities. (B) The intensity of bands was quantified by densitometry. Data are expressed as the mean \pm SD of triplicate experiments of three independent experiments.

We detected NF-кB translocation with immunofluorescence microscopy and Western blotting. As shown in Fig. 6A, NF-кB translocates to the nucleus in response to UVB irradiation. Treatment with EGCG (an antioxidant) significantly inhibits UVB-induced NF- $\kappa \mathrm{B}$ activation. DPI, an inhibitor of NADPH oxidase also inhibits UVB-induced NF- $\mathrm{KB}$ nucleus translocation, as revealed in Western blot analysis (Fig. 6B). These results suggest that UVB-induced $N F-\kappa B$ activation may involve NADPH oxidase-mediated generation of ROS, and may be associated with the regulation of MMPs in cell migration.

\section{Discussion}

Cataract is the most common pathology of the lens. It remains the leading cause of reversible blindness worldwide. The proliferation and migration of residual lens epithelial cells (LECs) at the equator and under the anterior lens capsule lead to the development of cataract and PCO. In our previous studies, we found that the abnormal migration and proliferation are associated with growth factors such as epidermal growth factor (EGF) (21). In the present study, we discovered that UV induces the migration of HLECs possibly leading to the cataract. It is then suggested that the action spectrum derived by UVB may help develop the hazard function for cataract and PCO formation.

MMPs were defined by their ability to degrade the extracellular matrix, which may play a very important role in cell migration. MMP-1 is specifically localized within lens
A

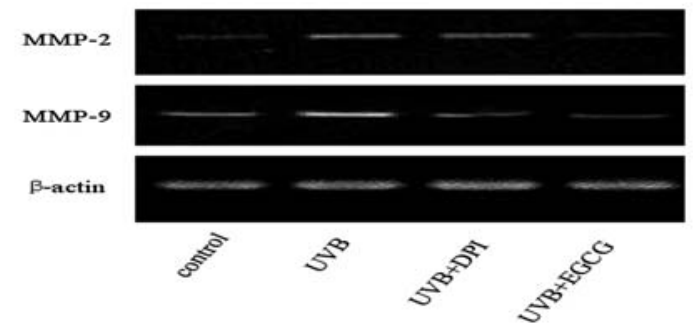

B

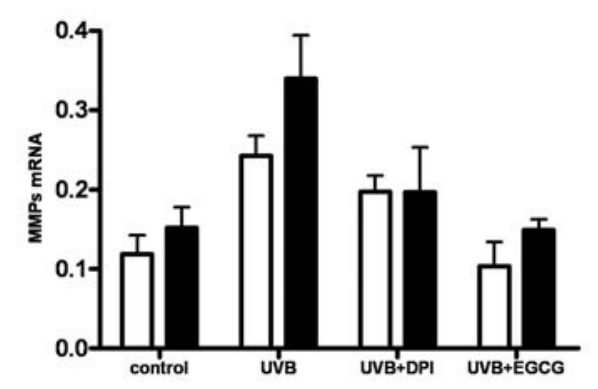

Figure 5. UVB up-regulates MMPs expression which is inhibited by DPI and EGCG. (A) RT-PCR analysis of MMP-2, MMP-9 mRNA and B-actin mRNA. HLECs were pre-incubated with DPI $(10 \mu \mathrm{M})$ or EGCG $(100 \mu \mathrm{g} / \mathrm{ml})$. After UVB irradiation, total RNAs were isolated at $24 \mathrm{~h}$ for RT-PCR with specific primers for MMP-2, MMP-9 and $\beta$-actin. (B) The relative expression of mRNA was normalized to $B$-actin. Data are expressed as the mean $\pm \mathrm{SD}$ of triplicate experiments of three independent experiments.

epithelium and cortical lens fibers of cortical cataract (7). MMP inhibitors have been shown to prevent human LEC migration and contraction of the lens capsule, suggesting that MMP inhibition may have a role in the therapeutic treatment of PCO (13). The matrix of LECs is composed primarily of collagen type IV and laminin which are known as the substrates for MMP-2 and MMP-9, these MMPs may be correlated to anterior subcapsular cataract. We found in this study that UVB induces LECs migration (Fig. 1). UVB also induces expression of MMP-2 and MMP-9 mRNA and their activities (Figs. 4 and 5). Our data suggest that UVB-induced cell migration is mediated by MMP-2 and MMP-9 regulation which may play a very important part in development of cataract and PCO.

Our results have indicated that UVB induces LECs migration which might be related to the development of a cataract. It has been shown that photo-absorption by cytoplasmic and membrane chromophores actually initiates responses to UVB radiation, often through generation of ROS. Our previous studies showed that UV-induced downregulation of Dsg-2, which is a highly organized intercellular junction that provides mechanical integrity to tissues by anchoring intermediate filaments to sites of strong adhesion, is mediated by ROS (19). I then present study, we also observed that UVB significantly increases intra-cellar ROS production, blocked by NADPH oxidase inhibitor DPI (Fig. 3). These data suggest that intra-cellar ROS production in response to UVB irradiation is not only in a physicochemical process but also made through the activation of 


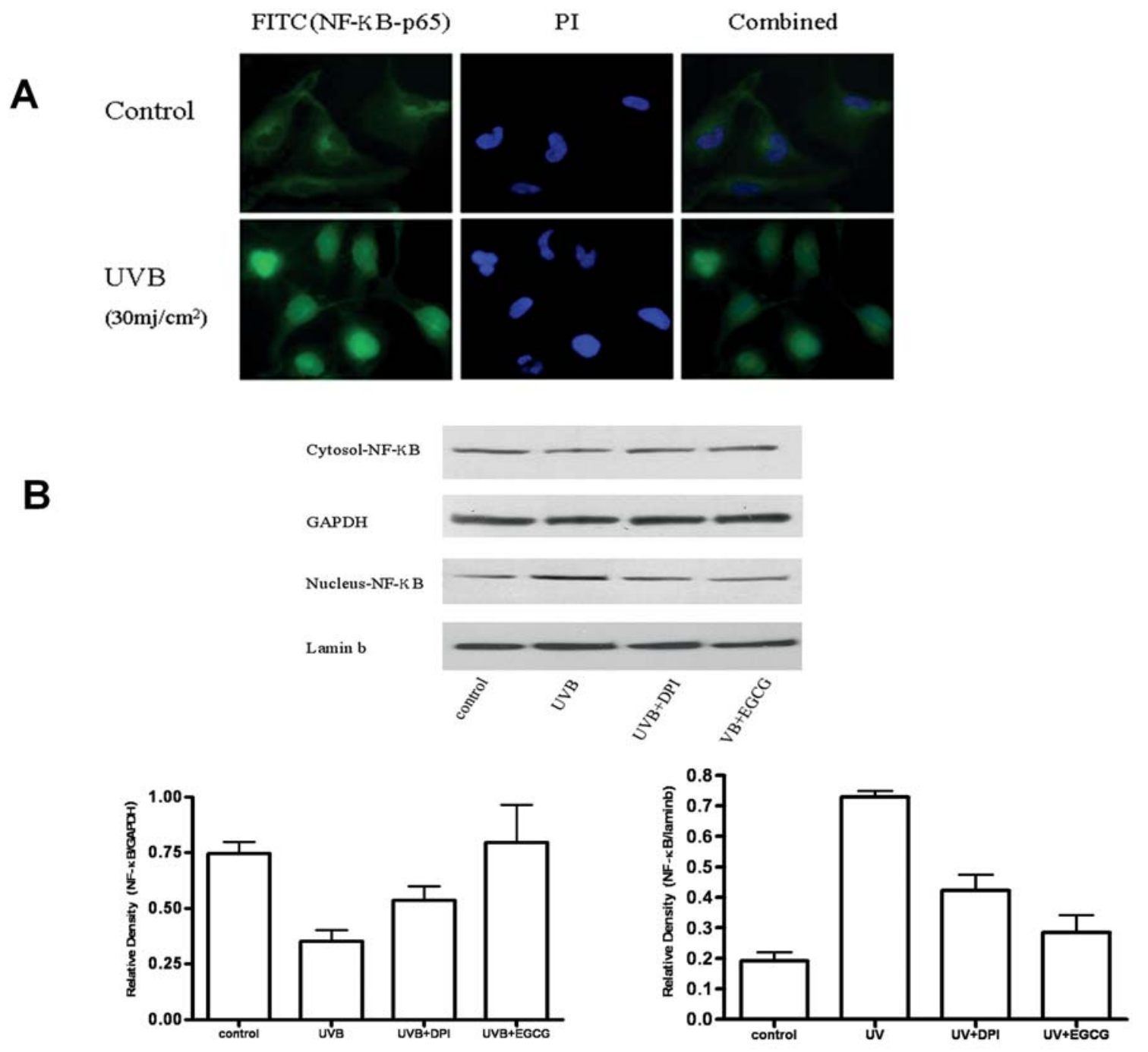

Figure 6. UVB induces nuclear translocation of NF-кB which is inhibited by DPI and EGCG. The fluorescence images (A) are representative of repeated experiments on the cells that were untreated and $4 \mathrm{~h}$ after UVB $\left(30 \mathrm{~mJ} / \mathrm{cm}^{2}\right)$ exposure: left column, FITC fluorescence detection to an NF- $\mathrm{B}$ p65 antibody; middle, PI staining; right, combined images. (B) Western blot analysis of cytosol and nucleus NF- $\mathrm{kB}$ p65 expression in LECs at $4 \mathrm{~h}$ after UVB (30 mJ/cm²) irradiation combined with or without DPI $(10 \mu \mathrm{M})$ or EGCG $(100 \mu \mathrm{g} / \mathrm{ml})$. (C and D) The relative intensity of cytosol or nucleus NF- $\mathrm{B}$ p65 was normalized to GADPH or Lamib. Data are expressed as the mean \pm SD of triplicate experiments of three independent experiments.

NADPH oxidase (Fig. 2). Treatment with DPI or EGCG reduces UVB-induced expression of MMPs mRNA level and activities (Figs. 4 and 5). These results suggest that the upregulation of MMPs by UVB may partly involve NADPH oxidase-mediated generation of ROS and may be associated with cell migration.

UVB-induced ROS has been suggested to play a role as second-messenger molecule in the cell signaling and regulation of expression of genes such as NF- $\mathrm{KB}$ which is involved in the expression of numerous genes responsible for various important cellular events. NF- $\mathrm{kB}$ regulates MMPs by binding to $N F-\kappa B$ consensus sequence present in their promoter regions. $\mathrm{NF}-\kappa \mathrm{B}$ pathway is a very important signal transduction and cell-specific regulation of MMPs (22). Several studies have suggested that ROS plays a major role in the activation of MMPs (23). While the exact mechanism remains to be further understood, our present study provides evidence that UVB induces $N F-\kappa B$ nucleus translocation (Fig. 6). Our result suggests that UVB irradiation induces $\mathrm{NF}-\kappa \mathrm{B}$ transcriptional regulation of several MMPs. The activation of NF-кB is inhibited effectively by EGCG and DPI, suggesting that UVB-induced NF- $\kappa \mathrm{B}$ activation may involve NADPH oxidase-mediated generation of ROS and may be involved in the regulation of MMPs and cell migration.

In conclusion, UVB radiation activates redox-sensitive transcription factor NF- $\mathrm{BB}$ through NADPH oxidase-mediated generation of ROS, resulting in up-regulation of MMPs and cell migration in HLECs. This study may eventually lead to the revealing of potential therapeutic targets for the treatment of subcapsular cataract.

\section{Acknowledgements}

This research was supported in part by a grant from Natural Science Foundation of Jiangsu Province, China (BK2007234, Q.J.), a grant from Natural Science Foundation of Jiangsu Higher Education Institutions of China (07KJD320140, Q.J.), a grant from Nanjing Foundation for Development of Science and Technology, China (200801093, Q.J.), a grant from Province Postdoctoral Science Foundation (Q.J.), a grant 
from Natural Science Foundation for Colleges and Universities in Jiangsu Province of China (Q.J.), and by a grant from NIH (P20 RR016457 from INBRE Program of the National Center for Research Resources, Y.W.).

\section{References}

1. West S: Epidemiology of cataract: accomplishments over 25 years and future directions. Ophthalmic Epidemiol 14: 173-178, 2007.

2. Wu K, Shui YB, Kojima M, Murano H, Sasaki K and Hockwin O: Location and severity of UVB irradiation damage in the rat lens. Jpn J Ophthalmol 41: 381-387, 1997.

3. Wang E, Reid B, Lois N, Forrester JV, McCaig CD and Zhao M: Electrical inhibition of lens epithelial cell proliferation: an additional factor in secondary cataract? FASEB J 19: 842-844, 2005.

4. Dillon J: UV-B as a pro-aging and pro-cataract factor. Doc Ophthalmol 88: 339-344, 1994.

5. Cejkova J and Lojda Z: Histochemical study on xanthine oxidase activity in the normal rabbit cornea and lens and after repeated irradiation of the eye with UVB rays. Acta Histochem 98: 47-52, 1996.

6. Kleiman NJ, Wang RR and Spector A: Ultraviolet light induced DNA damage and repair in bovine lens epithelial cells. Curr Eye Res 9: 1185-1193, 1990 .

7. Sachdev NH, Di Girolamo N, Nolan TM, McCluskey PJ, Wakefield D and Coroneo MT: Matrix metalloproteinases and tissue inhibitors of matrix metalloproteinases in the human lens: implications for cortical cataract formation. Invest Ophthalmol Vis Sci 45: 4075-4082, 2004.

8. Marcantonio JM, Rakic JM, Vrensen GF and Duncan G: Lens cell populations studied in human donor capsular bags with implanted intraocular lenses. Invest Ophthalmol Vis Sci 41: 1130-1141, 2000.

9. Saxby L, Rosen E and Boulton M: Lens epithelial cell proliferation, migration, and metaplasia following capsu-lorhexis. Br J Ophthalmol 82: 945-952, 1998.

10. Alexander CM and Werb Z: Proteinases and extracellular matrix remodeling. Curr Opin Cell Biol 1: 974-982, 1989.

11. Seomun Y, Kim J, Lee EH and Joo CK: Overexpression of matrix metalloproteinase- 2 mediates phenotypic transformation of lens epithelial cells. Biochem J 358: 41-48, 2001.

12. Wormstone IM, Tamiya S, Anderson I and Duncan G: TGFbeta2-induced matrix modification and cell transdifferentiation in the human lens capsular bag. Invest Ophthalmol Vis Sci 43: 2301-2308, 2002.
13. Wong TT, Daniels JT, Crowston JG and Khaw PT: MMP inhibition prevents human lens epithelial cell migration and contraction of the lens capsule. Br J Ophthalmol 88: 868-872, 2004.

14. Awasthi N, Wang-Su ST and Wagner BJ: Downregulation of MMP-2 and -9 by proteasome inhibition: a possible mechanism to decrease LEC migration and prevent posterior capsular opacification. Invest Ophthalmol Vis Sci 49: 1998-2003, 2008.

15. Wormstone IM, Tamiya S, Marcantonio JM and Reddan JR: Hepatocyte growth factor function and c-Met expression in human lens epithelial cells. Invest Ophthalmol Vis Sci 41: 4216-4222, 2000.

16. Fisher GJ, Datta SC, Talwar HS, Wang ZQ, Varani J, Kang S and Voorhees JJ: Molecular basis of sun-induced premature skin ageing and retinoid antagonism. Nature 379: 335-339, 1996.

17. Rhee JW, Lee KW, Sohn WJ, Lee Y, Jeon OH, Kwon HJ and Kim DS: Regulation of matrix metalloproteinase-9 gene expression and cell migration by NF-kappa B in response to CpG-oligodeoxynucleotides in RAW 264.7 cells. Mol Immunol 44: 1393-1400, 2007.

18. Fisher GJ, Kang S, Varani J, Bata-Csorgo Z, Wan Y, Datta S and Voorhees JJ: Mechanisms of photoaging and chronological skin aging. Arch Dermatol 138: 1462-1470, 2002.

19. Jiang Q, Zhou C, Healey S, Chu W, Kouttab N, Bi Z and Wan Y: UV radiation down-regulates Dsg-2 via Rac/NADPH oxidasemediated generation of ROS in human lens epithelial cells. Int J Mol Med 18: 381-387, 2006.

20. Jiang Q, Cao C, Zhou C, Song X, Healey S, Kouttab N, Chu W, $\mathrm{Xu}$ A, Bi Z and Wan Y: Quercetin attenuates UV- and $\mathrm{H}(2) \mathrm{O}(2)-$ induced decrease of collagen type I in cultured human lens epithelial cells. J Ocul Pharmacol Ther 24: 164-174, 2008.

21. Jiang Q, Zhou C, Bi Z and Wan Y: EGF-induced cell migration is mediated by ERK and PI3K/AKT pathways in cultured human lens epithelial cells. J Ocul Pharmacol Ther 22: 93-102, 2006.

22. Vincenti MP and Brinckerhoff CE: Signal transduction and celltype specific regulation of matrix metalloproteinase gene expression: can MMPs be good for you? J Cell Physiol 213: 355-364, 2007

23. Rajagopalan S, Meng XP, Ramasamy S, Harrison DG and Galis ZS: Reactive oxygen species produced by macrophagederived foam cells regulate the activity of vascular matrix metalloproteinases in vitro. Implications for atherosclerotic plaque stability. J Clin Invest 98: 2572-2579, 1996. 